\title{
Testing and Analysis of Concrete-Filled Square Hollow Section Stub Columns with Perfobond Leister Rib
}

\author{
Gao CHENG, Yongjian LIU, Hui LI, Ning ZHANG, Jufeng SU
}

\begin{abstract}
Perfobond Leister Rib (PBR) is found to improve the bond strength in concrete-filled hollow section and the capacity of the steel plate to resist local buckling. An experimental investigation of 12 test specimens is firstly carried out on the behavior of concrete-filled square hollow section CFSHS) stub columns with PBR. To examine different mechanical behaviors of the columns utilized in bridge or building structure, different loading methods are investigated; e.g., loading through steel alone, loading through concrete alone and loading through the whole cross section. The failure mode, strain distribution, ultimate strength and the confinement of the concrete core offered by the steel tube are studied. The test results showed that CFSHS tubular columns with PBR are emulative of the conventional columns. PBR can make the steel tube and filled-in concrete work together, which results in the axial load shared by hollow steel section and filled-in concrete section regardless of loading through steel or concrete alone. The axial strain distribution model of steel tube section along the height for CFSHS with PBR is proposed.
\end{abstract}

Keywords: concrete-filled hollow section; experiments; loading method; Perfobond Leister Rib; square hollow section; stub columns

\section{INTRODUCTION}

Concrete-filled steel tubular (CFST) structure not only has excellent mechanical performance, but also can be used as the formwork for pouring concrete in the pipe, so as to reduce the working procedure of installation and dismantling template, speed up the construction progress and save the cost. It has been employed as axial forceoriented component, such as arch rib, pier, chord member and web member [1]. With broadening applications and improving analytical ability to assess load-carrying capacity, many CFST columns in large cross-section size are emerging [2]. Limited by the manufacturing technology, processing quality and cost of steel plate, the thickness of steel tube can't be too large. That results in very big widthto-thickness ratio of steel tube, which is correlative with local buckling of the steel plate and interfacial debonding. Therefore, CFST stiffened with Perfobond Leister Rib (PBR) is proposed as a new type of cross-section for CFST column [2-4], a selection of which is depicted in Fig. 1.

Perfobond Leister (PBL) was invented and applied in bridge construction in German initially [5]. Recently, composite dowel consisting of PBL with clothoid strip and concrete has been preferred in both highway and railway composite bridge in German [6, 7]. Push-out experiments of PBL connector were carried out, strength equations were regressed based on the tests. After that, a total of 20 specimens of CFSHS stub columns were pushed out, which included three forms of steel pipe cross-section: no stiffener, setting stiffener and PBR [8]. It showed that setting PBR significantly improves local buckling resistance of specimens and bond strength. The shear behavior push-out test of the specimens with different PBR hole spacing, hole diameter, concrete coarse aggregate size was carried out by Liu. The arch joint in compression of CFST with PBR was further analyzed by Liu [9], and the transfer distance of shear force from steel tube to concrete column is decreased dramatically with the aid of PBR. An obvious decrease in the stress concentration factor was observed in concrete-filled rectangular hollow section joints with PBR, compared to hollow section rectangular joints, under both axial compression and axial tension in the brace, because the concrete infill and PBR restrict the inward and outward deformations of the chord's top plate [10]. The advantages on the mechanical properties of CFSHS structure stiffened using PBR were systematically expounded with respect to the behaviors of steel plate, interface, member and joint. Composite truss bridge with PBR-stiffened CFRHS members was competitive in mechanical performance and construction [11]. CFST columns with other stiffeners such as tensile bar and reinforcing bar could also restrain the outward deformation of concave corners and weld points, postpone the local buckling of steel tubes, improve the confinement of concrete in a certain extent, increase the bearing capacity and ductility of specimens and improve the failure mode of specimens [12, 13]. However, its production and installation process was a little complicated. PBR is found to improve the bond strength in concrete-filled hollow section and the capacity of the steel plate to resist local buckling.
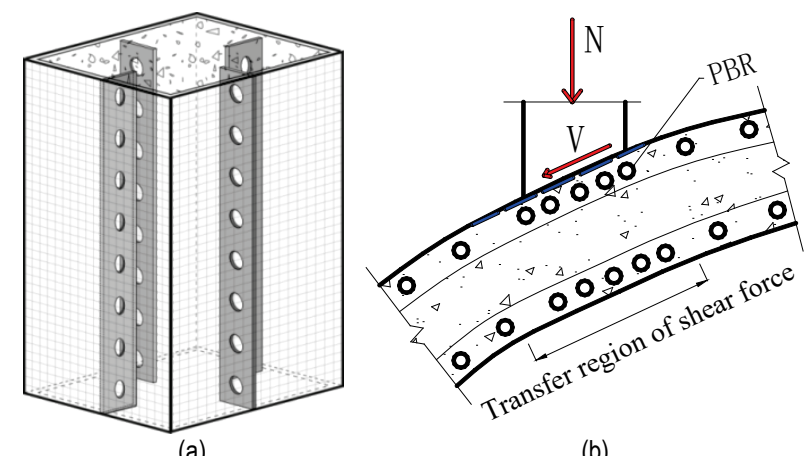

(b)

In the present investigation, a series of tests on CFSHS stub columns with PBR was performed. The experimental study focused not only on the axial compressive behavior of these composite sections, but also assessed confinement effects and mechanical property in different loading methods. Failure mode, ductility and ultimate strength were compared for a range of concrete grades and steel thicknesses. The results of the tests have been analyzed and compared with CFSHS without PBR. On the basis of the comparisons, the superiority of CFSHS stub columns with PBR have been presented. 


\section{EXPERIMENTAL PROGRAM}

\subsection{Description of Column Model}

A total of 12 concrete-filled square hollow section (CFSHS) stub columns were tested at the Chang'an University to assess the compressive resistance of CFSHS with PBR, and to examine the influences of loading methods. Tab. 1 summarized the characteristics of the test columns. The general detail of the columns was shown in Fig. 2 and Fig. 3. The plate thickness of columns including PBR was $3 \mathrm{~mm}$. Of 12 columns, 6 were CFSHS stub columns with PBR to compare loading method. The loading methods were shown in Fig. 4. Column was made by welding the two folded plate with PBR together as shown in Fig. 5. In order to reduce the error of the test results, each group contained two identical specimens.
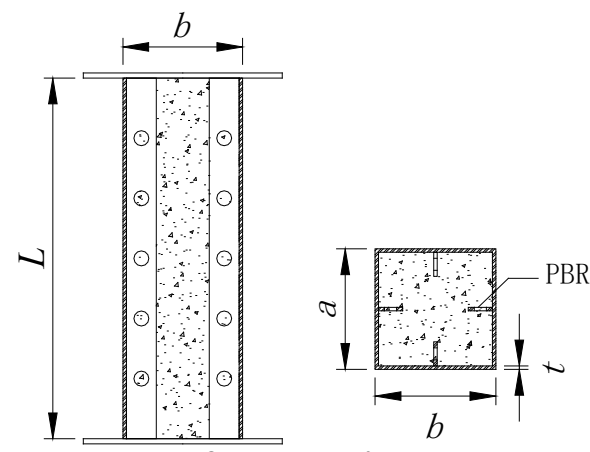

Figure 2 General detail of the columns

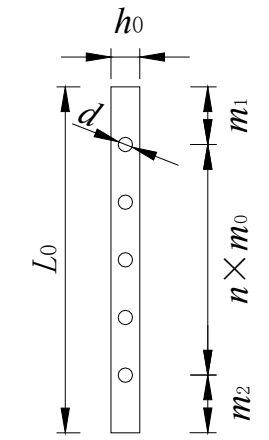

Figure 3 PBR configuration

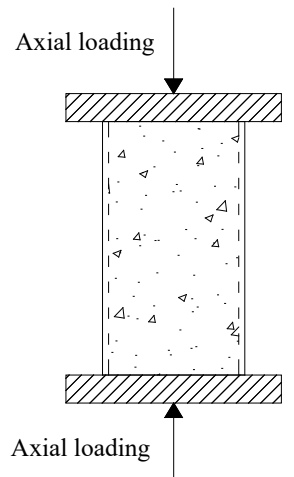

(a)

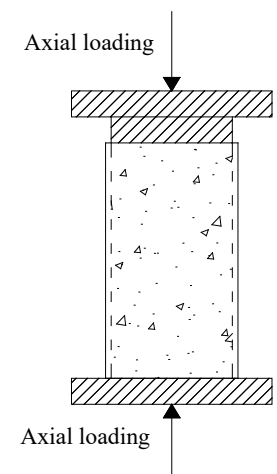

(b)

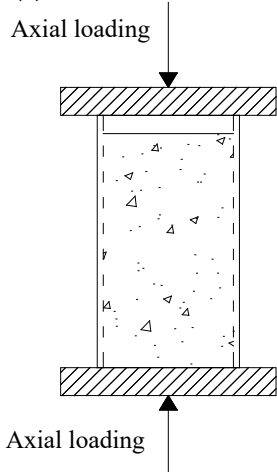

(c)

Figure 4 Loading method: a- Loading through the whole cross section, $b$ Loading through concrete alone, $\mathrm{c}$ - Loading through steel alone

All specimens including PBR were fabricated by Chinese Standard Q235 steel. Tensile coupon tests were conducted to determine the material mechanical properties. The coupon specimens were fabricated according to the recommendations of the Chinese code of metallic material test as shown in Tab. 2. The material properties of concrete were determined from the compressive concrete cubes tests. A total of 6 standard concrete cubes with the nominal length of $150 \mathrm{~mm}$ according to Chinese Code were poured and prepared. The material properties of the standard cubes are listed in Tab. 3, in which the mean value of the concrete strength is $50.5 \mathrm{MPa}$.

Table 1 Details of test specimens

\begin{tabular}{|c|c|c|c|c|c|c|c|c|c|}
\hline Specimen no. & $b \times a \times t(\mathrm{~mm})$ & $L(\mathrm{~mm})$ & Loading method & Concrete filled & PBR & $L_{0}(\mathrm{~mm})$ & $h_{0}(\mathrm{~mm})$ & $m_{0}\left(m_{1,2}\right)(\mathrm{mm})$ & $D(\mathrm{~mm})$ \\
\hline S-1-1 & $120 \times 120 \times 3$ & 360 & $\mathrm{c}$ & $\times$ & $\times$ & $\times$ & $\times$ & $\times$ & $\times$ \\
\hline S-1-2 & $120 \times 120 \times 3$ & 360 & $\mathrm{c}$ & $x$ & $\times$ & $\times$ & $x$ & $x$ & $x$ \\
\hline S-2-1 & $120 \times 120 \times 3$ & 360 & $\mathrm{c}$ & $x$ & $\sqrt{ }$ & 360 & 30 & 60 & 15 \\
\hline S-2-2 & $120 \times 120 \times 3$ & 360 & $\mathrm{c}$ & $x$ & $\sqrt{ }$ & 360 & 30 & 60 & 15 \\
\hline SC-1-1 & $120 \times 120 \times 3$ & 360 & $\mathrm{~b}$ & $\sqrt{ }$ & $x$ & $\times$ & $x$ & $\times$ & $\times$ \\
\hline SC-1-2 & $120 \times 120 \times 3$ & 360 & $\mathrm{~b}$ & $\sqrt{ }$ & $x$ & $\times$ & $\times$ & $\times$ & $\times$ \\
\hline P-1-1 & $120 \times 120 \times 3$ & 360 & $\mathrm{a}$ & $\sqrt{ }$ & $\sqrt{ }$ & 360 & 30 & 60 & 15 \\
\hline $\mathrm{P}-1-2$ & $120 \times 120 \times 3$ & 360 & $\mathrm{a}$ & $\sqrt{ }$ & $\sqrt{ }$ & 360 & 30 & 60 & 15 \\
\hline P-2-1 & $120 \times 120 \times 3$ & 360 & $\mathrm{c}$ & $\sqrt{ }$ & $\sqrt{ }$ & 360 & 30 & 60 & 15 \\
\hline P-2-2 & $120 \times 120 \times 3$ & 360 & $\mathrm{c}$ & $\sqrt{ }$ & $\sqrt{ }$ & 360 & 30 & 60 & 15 \\
\hline P-3-1 & $120 \times 120 \times 3$ & 360 & $\mathrm{~b}$ & $\sqrt{ }$ & $\sqrt{ }$ & 360 & 30 & 60 & 15 \\
\hline $\mathrm{P}-3-2$ & $120 \times 120 \times 3$ & 360 & $\mathrm{~b}$ & $\sqrt{ }$ & $\sqrt{ }$ & 360 & 30 & 60 & 15 \\
\hline
\end{tabular}

Table 2 Material properties of steel

\begin{tabular}{|c|c|c|c|}
\hline No. & $\begin{array}{c}\text { Yield strength } \\
f_{\mathrm{y}}(\mathrm{MPa})\end{array}$ & $\begin{array}{c}\text { Mean value } \\
(\mathrm{MPa})\end{array}$ & $\begin{array}{c}\text { Young's modulus } \\
E_{\mathrm{s}}(\mathrm{MPa})\end{array}$ \\
\hline 1 & 228.4 & \multirow{2}{*}{229.0} & $2.06 \times 10^{5}$ \\
\hline 2 & 229.7 & & 2 \\
\hline
\end{tabular}

Table 3 Material properties of concrete

\begin{tabular}{|c|c|c|c|}
\hline No. & $\begin{array}{c}\text { Compressive cube } \\
\text { strength } f_{\text {cu }}(\mathrm{MPa})\end{array}$ & $\begin{array}{c}\text { Mean value } \\
(\mathrm{MPa})\end{array}$ & $\begin{array}{c}\text { Young's modulus } \\
E_{\mathrm{c}}(\mathrm{MPa})\end{array}$ \\
\hline 1 & 53.3 & \multirow{3}{*}{50.5} & \\
\hline 2 & 48.8 & & \multirow{2}{*}{$3.46 \times 10^{4}$} \\
\hline 3 & 53.3 & & \\
\hline 4 & 50.5 & & \\
\hline 5 & 50.7 & & \\
\hline 6 & 46.5 & & \\
\hline
\end{tabular}




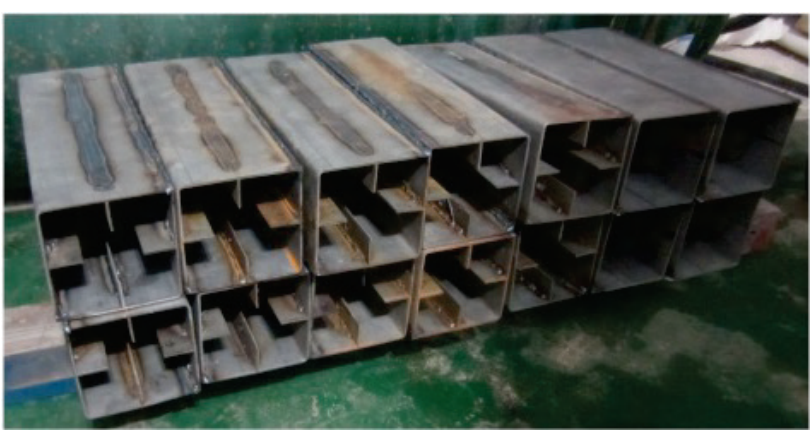

(a)

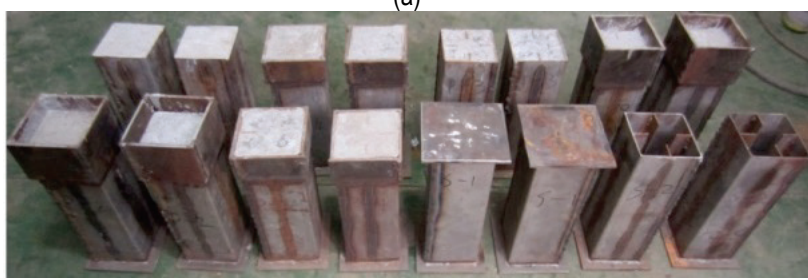

(b)

Figure 5 Manufacture of specimens: a - Manufacture of hollow section stub columns, $b$ - Concrete-filled square hollow section stub columns

\subsection{Test Setup and Loading Protocol}

All stub column tests were performed in a $2000 \mathrm{kN}$ capacity testing machine, which is shown in Fig. 6(b). Eight horizontal strain gauges (to measure hoop strains) and eleven vertical strain gauges (to measure axial strains) were affixed to each specimen, in the locations shown in Fig. 6(a). All strain gauges were located on the outer plate of the square steel tubes. Axial shortening of the specimens was captured by means of a linear variable displacement transducer positioned between the end platens of the testing machine. Axial loading was measured by pressure pickup built in testing machine. Horizontal strain, vertical strain and displacement transducer were collected in TDS 303 static strain gauge.

Before the test loading, the geometric alignment of the specimen was firstly carried out, and then the preload was subjected to eliminate inelastic deformation and inspect the state of inspection instrument and each gauge sensor. Ultimate load was preliminarily estimated by finite element analysis to improve loading validity. Loading protocol was applied force firstly and then displacement. Before reaching $75 \%$ of the estimated ultimate load, the load increment was $1 / 25$ of the estimated ultimate load. Subsequently loading displacement rate was about $2.5 \mathrm{~mm}$ per minute. The loading test was finished until axial loading dropping to $70 \%$ of ultimate load.

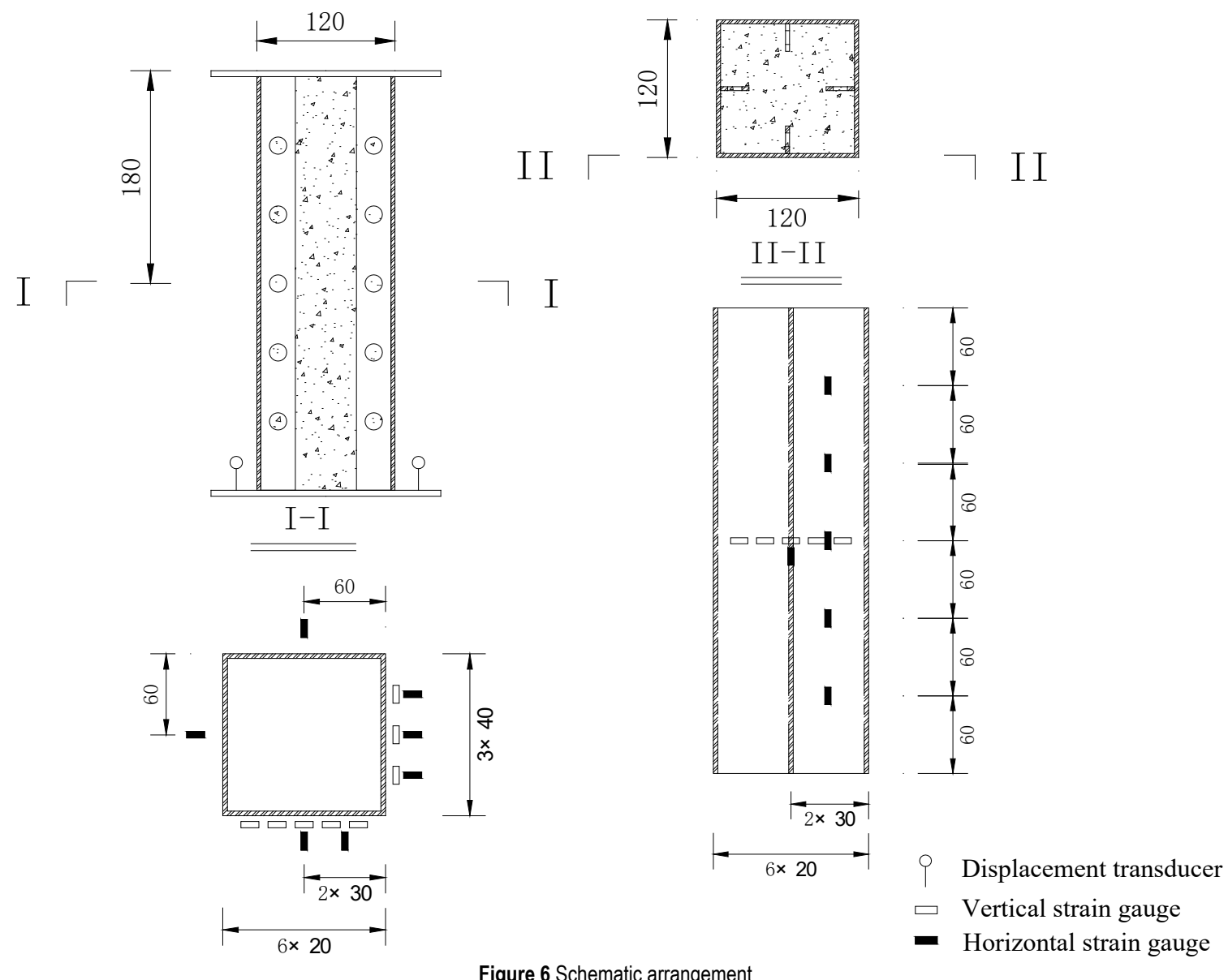

Figure 6 Schematic arrangement 


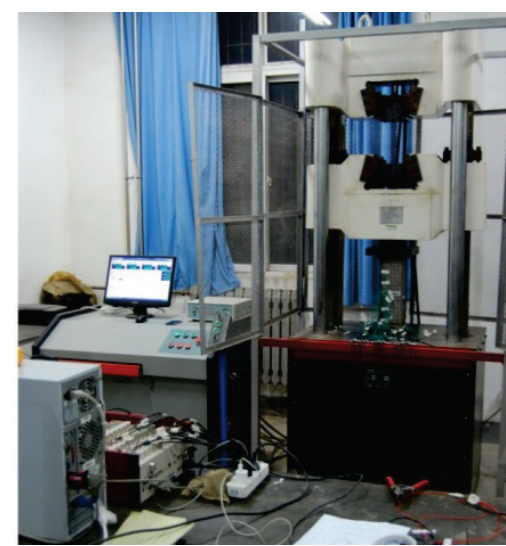

Figure 7 Testing machine

\section{ANALYSIS OF EXPERIMENTAL RESULTS}

\subsection{Mode of Failure}

The failure mode of the columns is summarized in Fig. 8. The characteristic of mode A corresponding to square hollow section (SHS) stub column shown in Fig. 8(a) is as follows: the angle of its corner is kept right, the middle of the adjacent steel plate is buckled inward and outward respectively, and the plate deformation is emerged as "single wave". The characteristic of mode B corresponding to SHS stub column with PBR shown in Fig. 8(b) is different from Mode A. Its deformation is emerged as "double wave", and the angle between the plate and PBR is also kept right. The characteristic of mode $\mathrm{C}$ corresponding to CFSHS stub column is shown in Fig. 8(c) Its plate is only buckled outward for CFSHS, which is different from SHS. The characteristic of mode D and mode E corresponds to CFSHS stub column with PBR. If the stiffness of PBR is large enough, the columns fail in mode E manifested as "double wave". Otherwise, the plate emerges as "single wave", whose failure mode is the same as CFSHS without PBR.

It is found that each specimen had no obvious steel plate buckling before reaching ultimate load. After that, the buckling deformation is gradually strengthened with the increase of the displacement. The sound caused by the sliding of the steel plate and the concrete interface is heard on CFSHS with PBR loading through concrete alone and loading through steel alone. After the completion of the test, the external damage is observed in Fig. 9. The external damage of each specimen emerges as well as the failure mode shown in Fig. 9. The failure of CFSHS with PBR loading through the whole cross section steel or loading through steel alone is conformed to Mode E. The failure of CFSHS with PBR loading through concrete alone is in accord with Mode D, which is consistent with CFSHS without PBR.

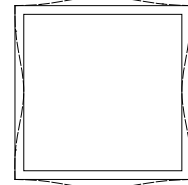

(a)

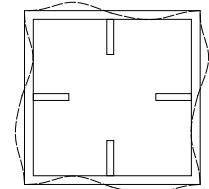

(b)

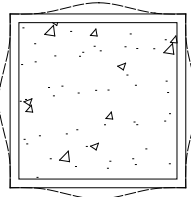

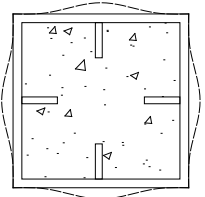

Figure 8 Mode of failure: a - Mode A, b - Mode B, c - Mode C, d - Mode D, e - Mode E

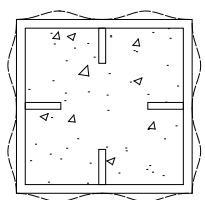

(e)

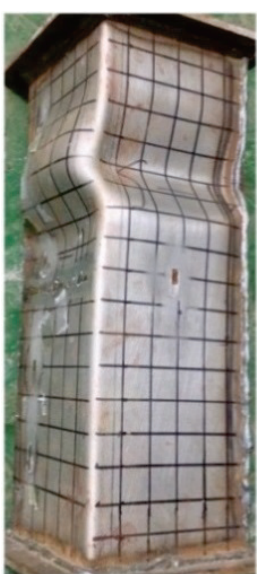

(a) S-1

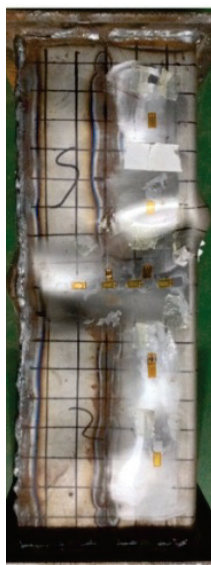

(b) S-2

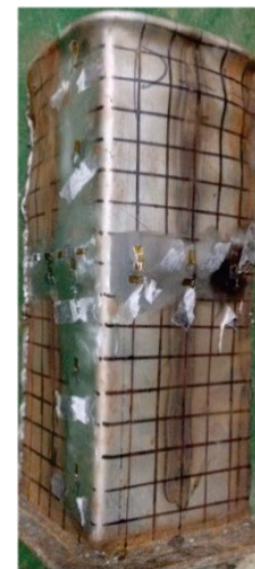

(c) P-1

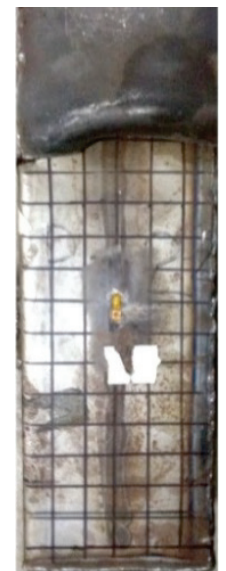

(d) P-2

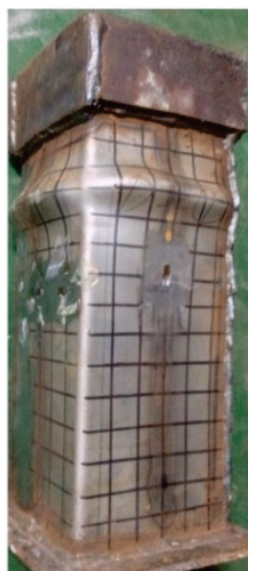

(f) P-3

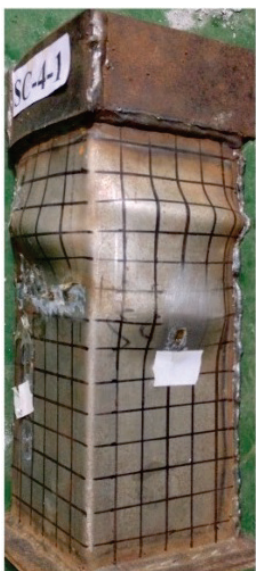

(g) SC-1

Figure 9 Observed external damage

In order to investigate the working mechanism of PBR, the steel plate is stripped. The observed interior damage is shown in Fig. 10. For CFSHS stub columns with PBR, the inner concrete close to bending deformation of steel plate is crushed, but the steel plate and concrete did not separate. On the contrary, the steel plate and concrete separated on CFSHS without PBR. Because of PBR, the deformation amplitude of steel plate is diminished.

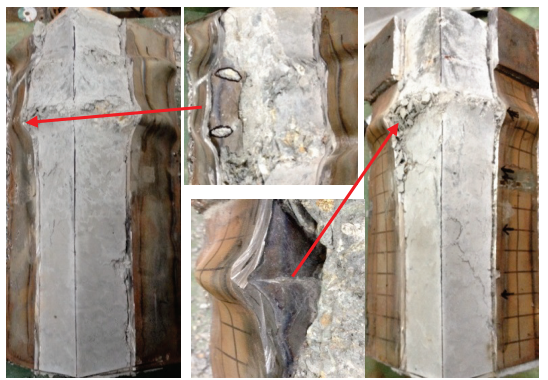

(a) P-1

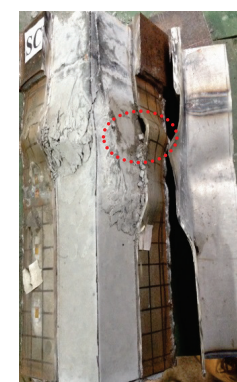

(c) SC-1

Figure 10 Observed interior damage 


\subsection{Force-Displacement Relationship}

The typical load versus displacement curves are shown in Fig. 11(a) for specimens loading through steel alone, in Fig. 11(b) for specimens loading through concrete alone or the whole cross section. It can be seen from Fig. 11(a) that the compression strength of CFSHS has a significant improvement due to PBR. This may boil down to its strong bond strength in concrete-filled hollow section. From Fig. 11(b), it can be observed the compression strength of CFSHS is similar to loading through concrete or loading through the whole cross section, but is slightly higher than the specimens without PBR. PBR functioned as shear joint evidently improves the bond strength in concrete-filled hollow section.

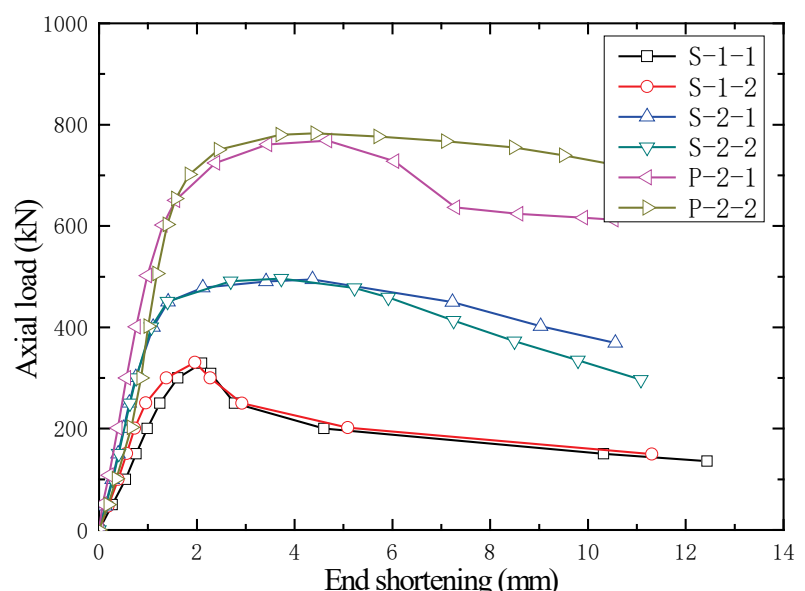

(a)

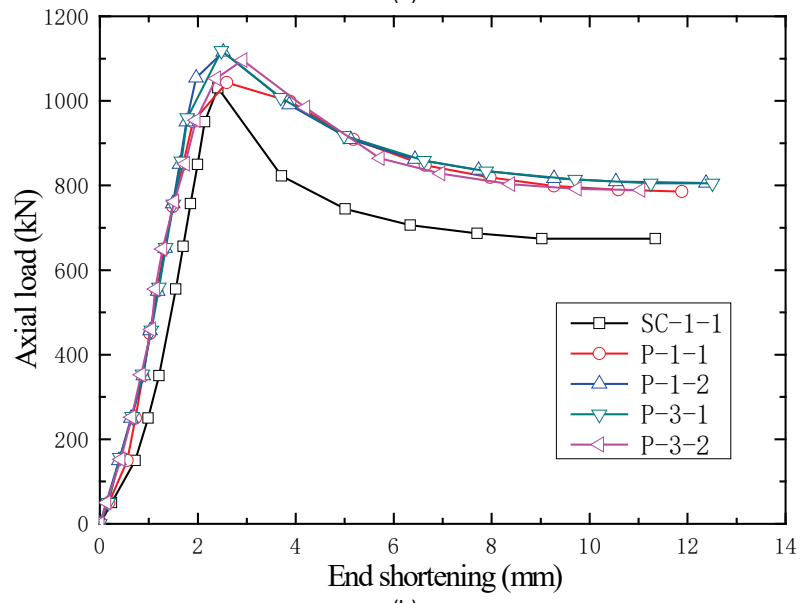

(b)

Figure 11 Load versus end shortening curve: a - Specimens loading through steel alone, $b$ - Specimens loading through concrete alone or the whole cross section

The results of Fig. 11 show that the ductility of the specimens, as well as their section resistance, is influenced by the presence of PBR. The ductility of the specimens is assessed in terms of the Ductility Index $D I$, as adopted by H. [14], and given by Eq. (1).
$D I=\frac{\delta_{85 \%}}{\delta_{\mathrm{u}}}$

where $\delta_{\mathrm{u}}$ is the end shortening of the specimen at ultimate load and $\delta_{85 \%}$ is the end shortening at which the strength of the specimen has dropped to $85 \%$ of the ultimate load. The values of $D I$ of the test specimens are listed in Tab. 4. From Tab. 4 and Fig. 10, it may be observed that the specimens with PBR display greater ductility, owing to the stronger stiffness. Loading method had little effect on ductility of the CFSHS stub columns with PBR.

Table 4 Summary of test results and behavioral indices

\begin{tabular}{|c|c|c|c|c|c|}
\hline $\begin{array}{c}\text { Specimen } \\
\text { no. }\end{array}$ & $b \times a \times t(\mathrm{~mm})$ & $\begin{array}{c}\text { Loading } \\
\text { method }\end{array}$ & $N_{\mathrm{u}}(\mathrm{kN})$ & $\delta_{\mathrm{u}}(\mathrm{mm})$ & $\mathrm{DI}$ \\
\hline $\mathrm{S}-1-1$ & $120 \times 120 \times 3$ & $\mathrm{c}$ & 329 & 2.10 & 1.2 \\
\hline $\mathrm{S}-1-2$ & $120 \times 120 \times 3$ & $\mathrm{c}$ & 331 & 1.96 & 1.3 \\
\hline $\mathrm{S}-2-1$ & $120 \times 120 \times 3$ & $\mathrm{c}$ & 494 & 4.36 & 1.6 \\
\hline $\mathrm{S}-2-2$ & $120 \times 120 \times 3$ & $\mathrm{c}$ & 496 & 3.73 & 2.2 \\
\hline $\mathrm{SC}-1-1$ & $120 \times 120 \times 3$ & $\mathrm{~b}$ & 1030 & 2.41 & 1.4 \\
\hline $\mathrm{P}-1-1$ & $120 \times 120 \times 3$ & $\mathrm{a}$ & 1043 & 2.59 & 2.1 \\
\hline $\mathrm{P}-1-2$ & $120 \times 120 \times 3$ & $\mathrm{a}$ & 1116 & 2.52 & 1.8 \\
\hline $\mathrm{P}-2-1$ & $120 \times 120 \times 3$ & $\mathrm{c}$ & 768 & 4.67 & 1.5 \\
\hline $\mathrm{P}-2-2$ & $120 \times 120 \times 3$ & $\mathrm{c}$ & 782 & 4.42 & 2.6 \\
\hline $\mathrm{P}-3-1$ & $120 \times 120 \times 3$ & $\mathrm{~b}$ & 1118 & 2.48 & 1.9 \\
\hline $\mathrm{P}-3-2$ & $120 \times 120 \times 3$ & $\mathrm{~b}$ & 1095 & 2.92 & 1.7 \\
\hline
\end{tabular}

\subsection{Measured Strains}

According to the force-displacement relationship and the failure mode, the specimens remain in elastic stage before reaching $80 \%$ of the ultimate load. As is known, the axial load must be equal along the height of the specimens, which is shared by hollow steel section and filled-in concrete section. Therefore, the axial stress of steel section can reflect the distribution of axial load along the height of the columns, which is measured by horizontal strain gauge shown in Fig. 12. It can be seen from Fig. 12(a) that the axial strain distribution of steel tube section is approximately uniform along the height for CFSHS with PBR loading through the whole section. As for CFSHS with PBR loading through steel alone, the axial strain is high from the end to half the height. After that, the strain begins to shrink and then stay the same until $7 / 12$ of the height, which is observed from Fig. 12(b). From Fig. 12(c), the strain distribution for CFSHS with PBR loading through concrete alone is similar to CFSHS with PBR loading through steel alone, but breaks closer to the end. By contrast, the strain of CFSHS loading through concrete alone is shown in Fig. 12(d). Its strain distribution is basically linear decline. In summary, the strain distribution is concluded in Fig. 12(e). We can see that the axial load is ultimately shared by hollow steel section and filled-in concrete section regardless of loading through steel or concrete alone because of PBR. PBR is a type of shear connector, which improves the combination action of CFSHS stub columns. 

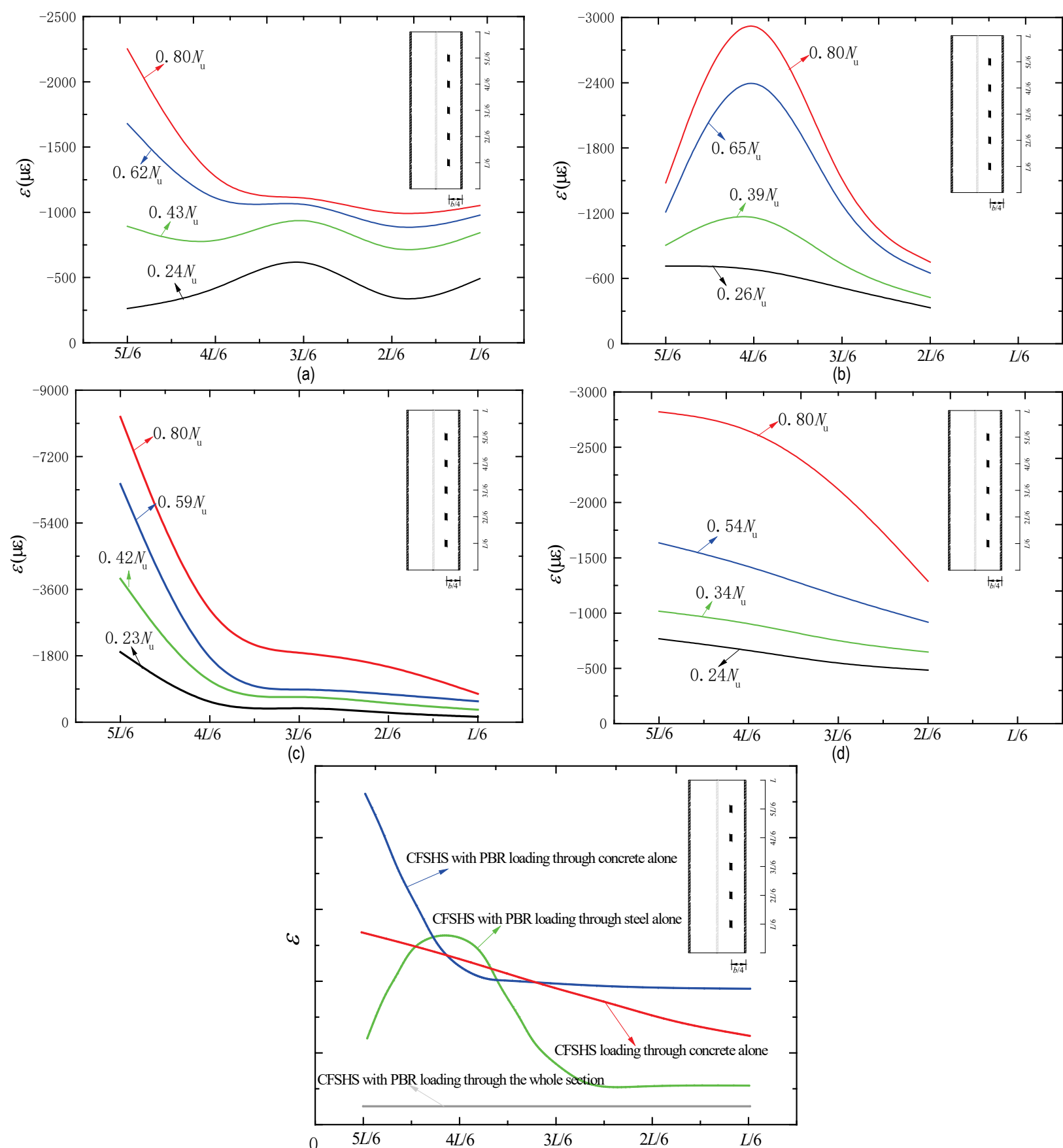

(e)

Figure 12 Distribution of horizontal strain gain: a - CFSHS with PBR loading through the whole section, b - CFSHS with PBR loading through steel alone, c - CFSHS with PBR loading through concrete alone, $d$ - CFSHS loading through concrete alone, e - strain summary

\subsection{Confining Effect}

The confining effect of CFSHS stub columns was assessed in terms of nominal Poisson's ratio $\left(v_{\mathrm{s}}{ }^{\prime}\right)$, as adopted by Chen [15] and defined as the negative ratio of transverse and longitudinal strains on steel plated. When the nominal Poisson's ratio exceeds the Poisson's ratio of steel material, the transverse deformation of concrete is restrained by the steel tube, and the confining effect begins to play a role. On this basis, Liu [16] proposed that the transverse and longitudinal strain gauge should be arranged at $1 / 4$ transverse cross section of steel plate to analyze confining effect, but not the central section connecting with PBR. The nominal Poisson's ratio of CFSHS stub columns is shown in Fig. 13. The strength of the confining effect and the time of its emergence can be observed from Fig. 13.

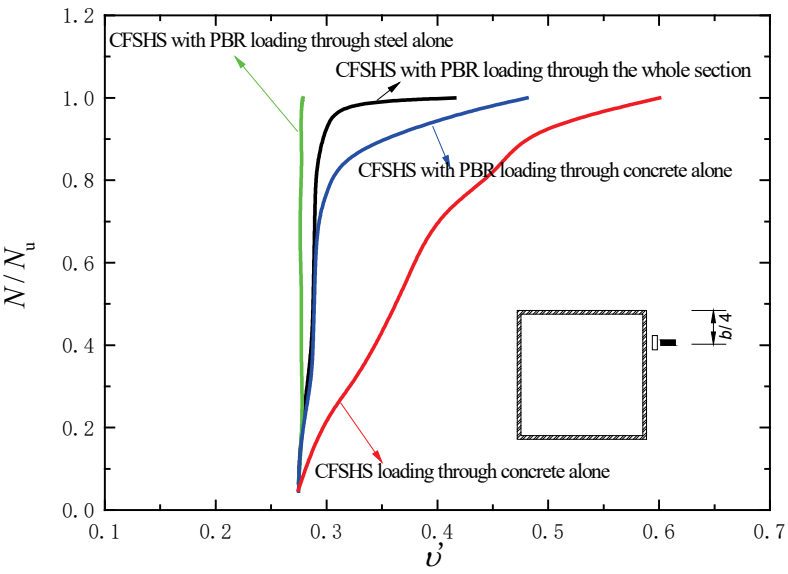

Figure 13 Nominal Poisson's ratio versus axial compression ratio curve 
As for CFSHS specimens with PBR, confining effect is potty for the specimens loading through the whole section and loading through steel alone. Confining effect comes into play for the specimens loading through concrete alone after reaching $70 \%$ of the ultimate load. Instead, confining effect comes with axial load applied for CFSHS specimens loading through concrete alone. It proves once again that PBR can make the steel tube and filled-in concrete work together.

\section{ANALYTICAL INVESTIGATION \\ 4.1 Model Description and Verification}

The numerical simulations of CFSHS stub columns with PBR are carried out using the FE package ABAQUS [17] to evaluate the bearing capacity. A comprehensive parametric study is performed to estimate the influence of the key parameters on the columns, namely: steel area ratio $(\alpha)$, yield strength of steel $\left(f_{\mathrm{y}}\right)$, and concrete compression strength $\left(f_{\mathrm{c}}\right)$. The range of validity of the parameters spring from engineering scale model is as follows: $8.3 \% \leq \alpha \leq 13.8$, $235 \leq f_{\mathrm{y}} \leq 420,15 \leq f_{\mathrm{c}} \leq 50$. The change of steel area ratio $(\alpha)$ is realized by simply altering steel plate thickness from $3 \mathrm{~mm}$ to $1.5 \mathrm{~mm}$.

Three-dimensional 4-node reduced shell elements are used to model the steel tube, and three-dimensional 8-node reduced solid elements are used to model the concrete and PBR. Mesh sensitivity analysis is carried out to get the optimal mesh refinement. As for plastic analysis, nonlinear material properties are used. The constitutive relation of the steel tube is assumed elastic-perfectly plastic body. Young's modulus $\left(E_{\mathrm{s}}\right)$ and Poisson's ratio $\left(v_{\mathrm{s}}\right)$ of the steel tube are assumed $206 \mathrm{GPa}$ and 0.283 , respectively. The ultimate strength of the steel tube is assumed as nominal buckling strength of steel, which is adopted according to the Chinese standard GB50017-2017. The same material properties are assigned to the PBR. The concrete filled in the steel tube is assigned a Poisson's ratio $\left(v_{\mathrm{c}}\right)$ of 0.167 , while its Young's modulus $\left(E_{\mathrm{c}}\right)$ depends on the concrete strength. The constitutive relation of the concrete using concrete damage model in ABAQUS is adopted according to the Chinese standard GB50010-2010, which is shown in Fig. 14.

As the adhesion between the concrete core and steel tube is too small, it is assumed that interfacial tension in the normal direction to the interface leads to separation between steel and concrete, whereas under compression, a contact relationship is assumed in the normal direction. This was modeled using 'cohesive contact' in ABAQUS, where the steel tube was selected as the "master" surface and the concrete was selected as the 'slave' surface [18]. The constitutive of the interface is adopted in Liu $[19,20]$ according to a large number of interface ejection tests and push-off tests. The loading and boundary conditions are modeled with axial test. The specimens P-1, P-3 and SC-1 are picked as FEM verification cases. FEM ultimate compression capacity and deformation are compared to test results as shown in Figs. 15-16, which was in good accordance with test result.

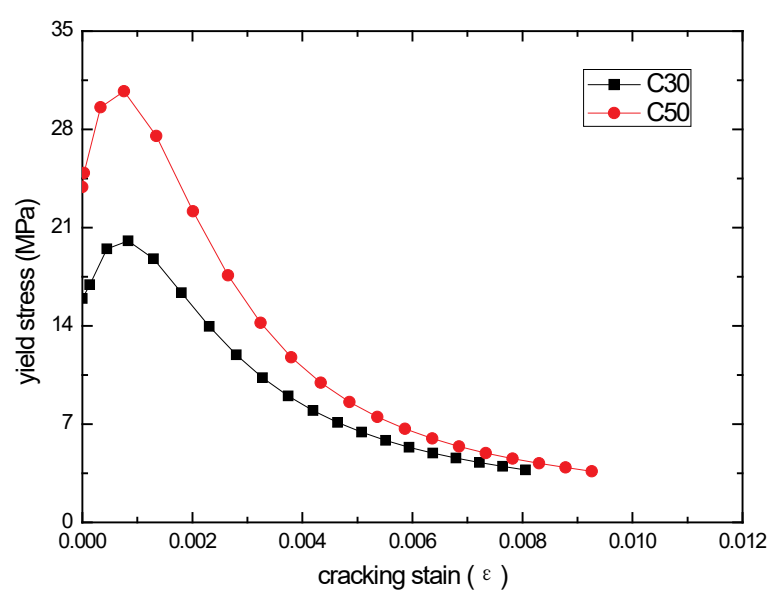

(a)

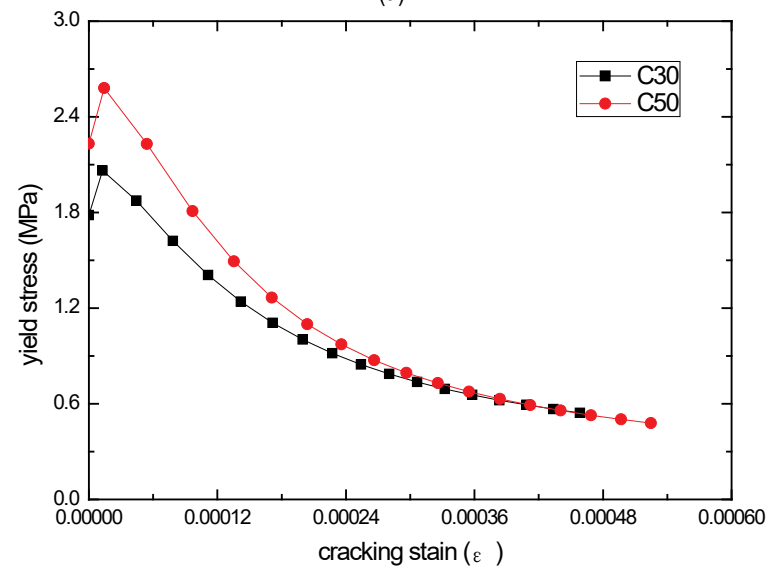

(b)

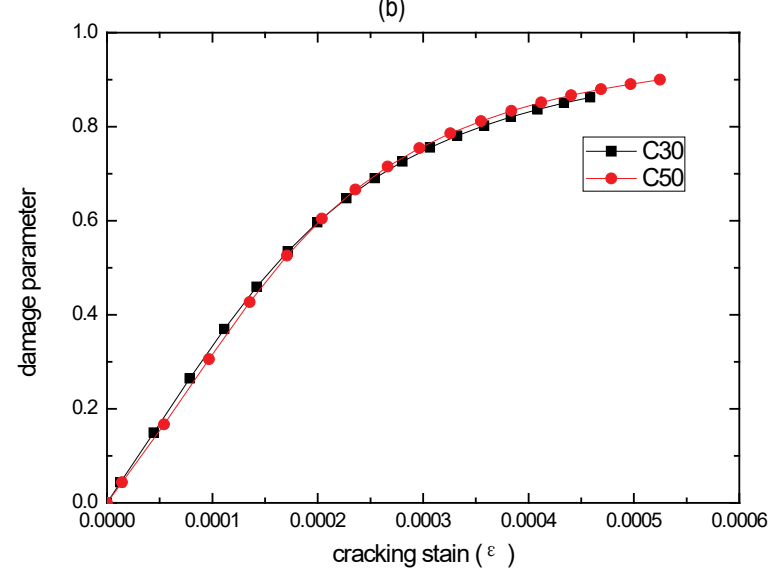

(c)

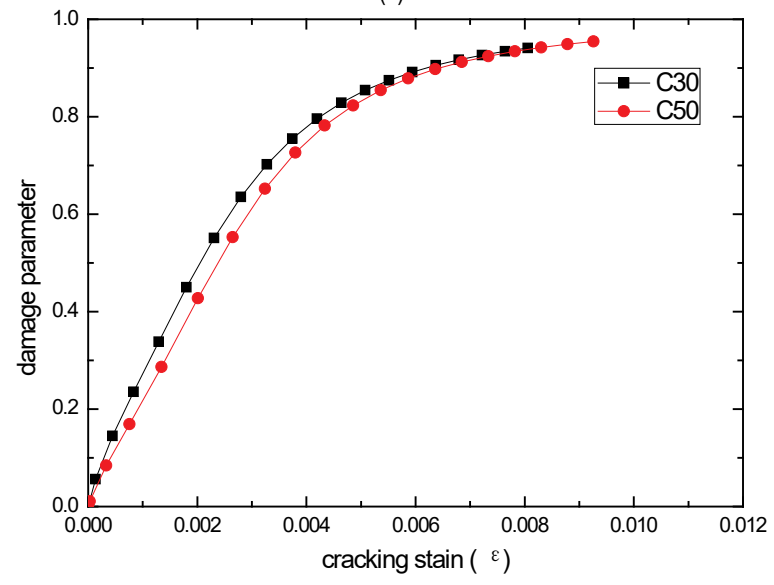

(d)

Figure 14 Constitutive relation of the concrete: a - Concrete compressive behavior, $b$ - Concrete tensile behavior, $c$ - Concrete tensile damage, $d$ Concrete tensile damage 


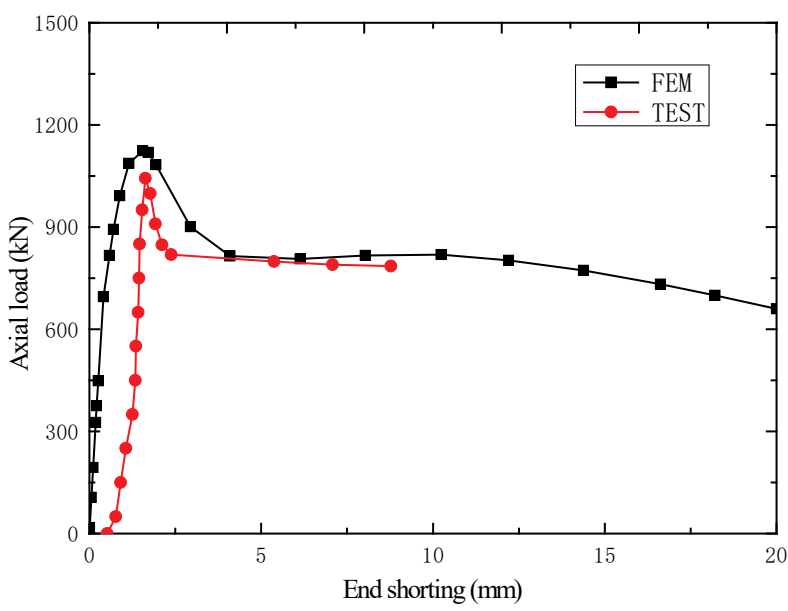

(a) P-1

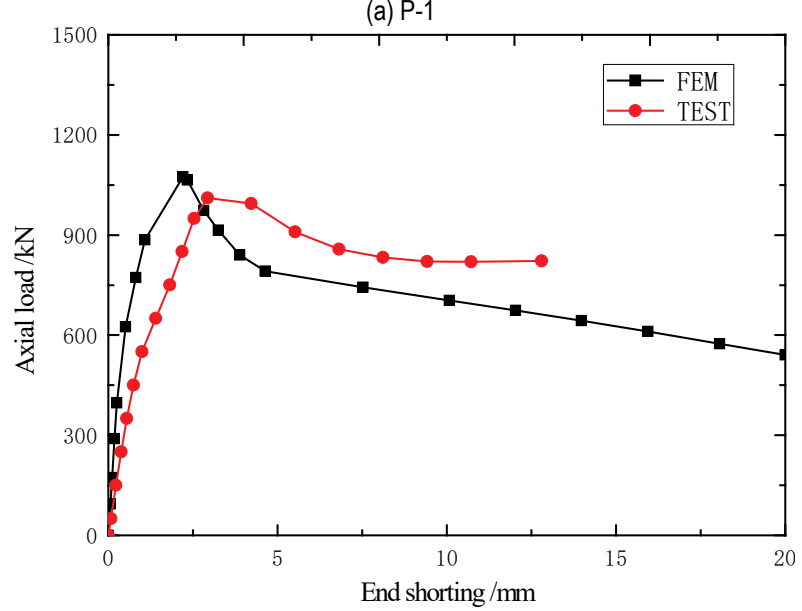

(b) P-3

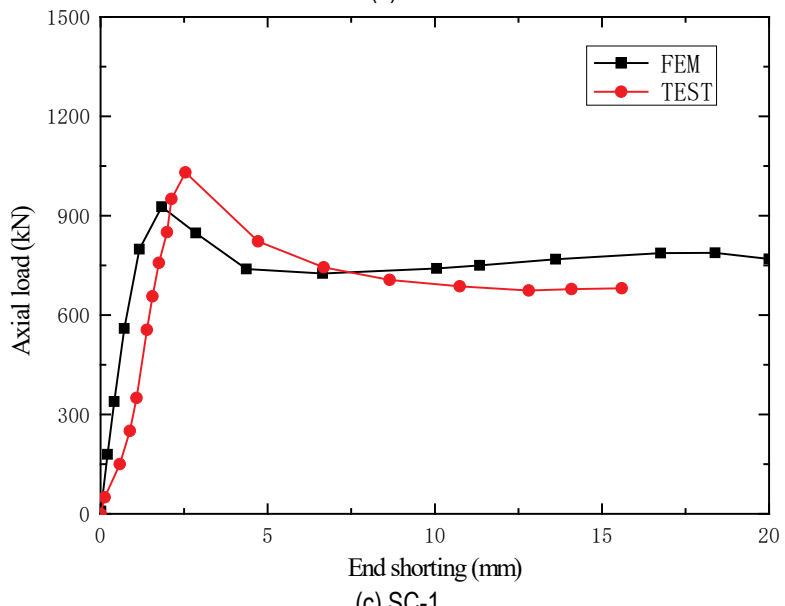

(c) SC-1

Figure 15 Experimental and FEM comparison of load versus end shorting curves

\subsection{Analytical Simulation Results}

According to the FEM results, the compression strength of CFSHS stub columns has a significant relevance to PBR indifferent parameter such as $\alpha, f_{\mathrm{y}}, f_{\mathrm{c}}$, which were shown in Figs. 17-19. It can be observed from Figs. 17-19 that the ultimate compression strength of CFSHS stub columns loading through concrete or steel alone is remarkably increased by PBR besides the contributions of loading methods and the parameter such as $\alpha, f_{\mathrm{y}}, f_{\mathrm{c}}$. As for CFSHS stub columns with PBR, its ultimate compression strength is similar to loading through concrete alone or loading through the whole cross section. However, its ultimate compression strength loading through the whole cross section is observably higher than that loading through concrete alone for CFSHS stub columns without PBR. The conclusions are still valid even in different parameter such as $\alpha, f_{\mathrm{y}}, f_{\mathrm{c}}$.

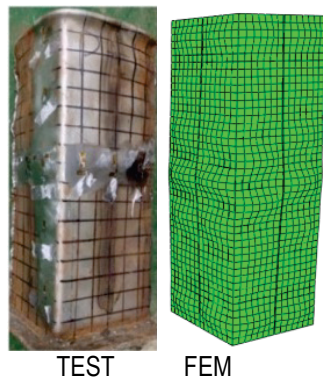

(a) $\mathrm{P}-1$

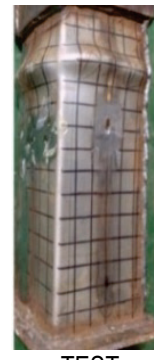

TEST

(b) P-3

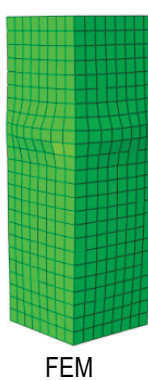

FEM
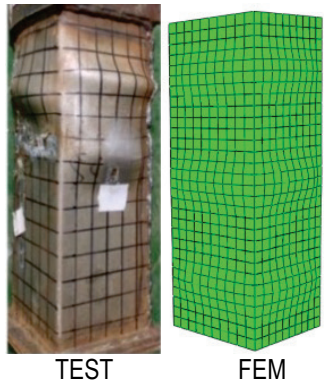

(c) SC-1

Figure 16 Experimental and FEM comparison of deformation

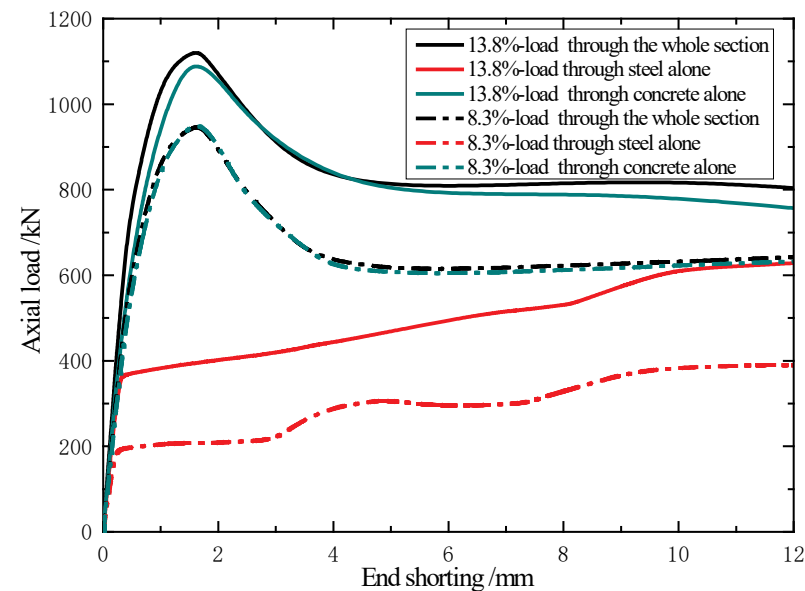

(a)

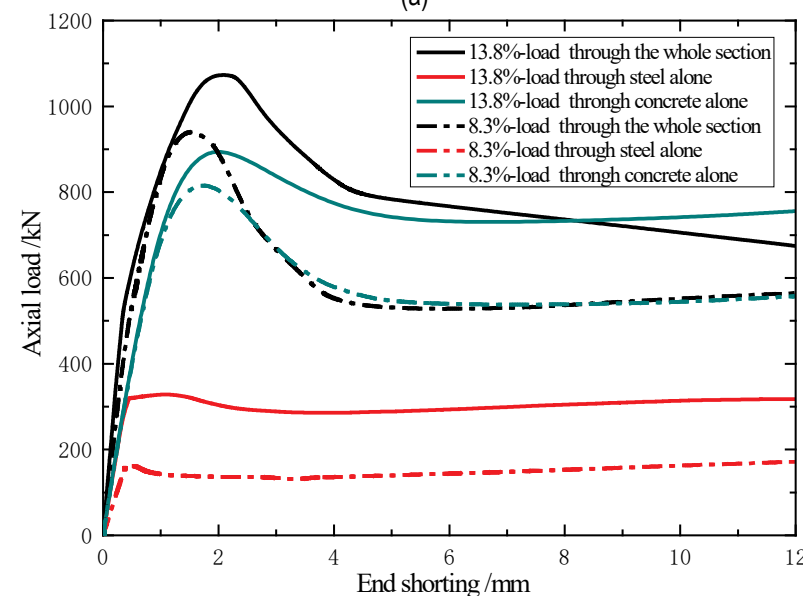

(b)

Figure 17 Load versus end shortening curve influnced by $\alpha$ : a - SHCFST stub columns with PBR, $b$ - SHCFST stub columns 


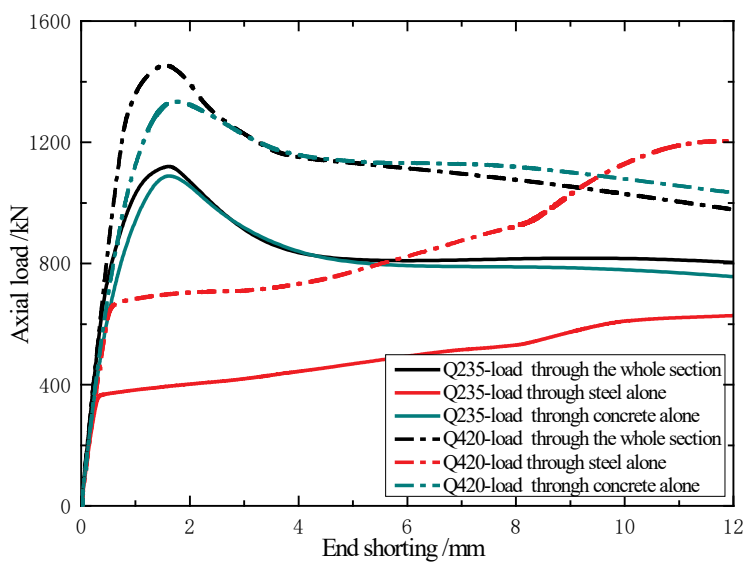

(a)

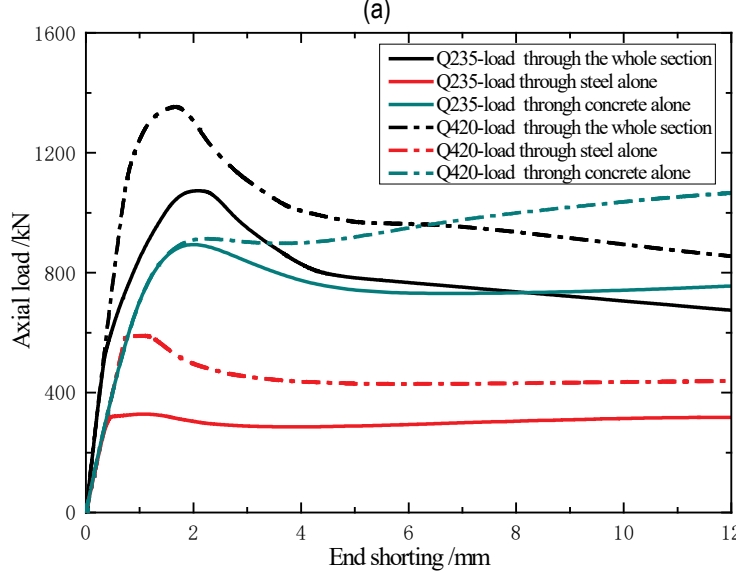

(b)

Figure 18 Load versus end shortening curve influnced by $f_{\mathrm{y}}$ : a - SHCFST stub columns with PBR, b - SHCFST stub columns
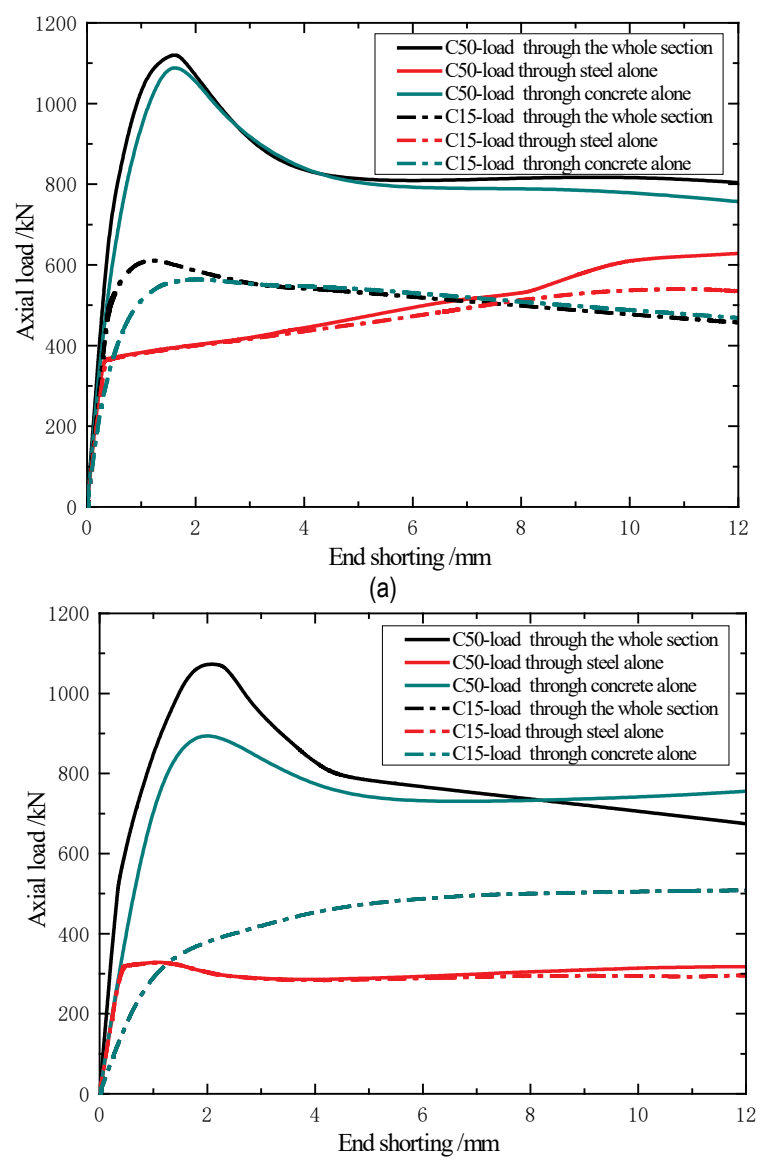

(b)

Figure 19 Load versus end shortening curve influnced by $f_{c}$ : a - SHCFST stub columns with PBR, b - SHCFST stub columns

\section{SUMMARY AND CONCLUSIONS}

This paper is based on experimental data and analytical investigation on concrete-filled square hollow section (CFSHS) stub columns with PBR. The following observations and conclusions are made based on the work described in this paper:

(1) PBR is found to improve the ultimate compression strength of CFSHS stub columns. Especially, the columns loading through concrete or steel alone are remarkably increased by PBR.

(2) Its ultimate compression strength is similar for CFSHS stub columns with PBR loading through concrete alone or loading through the whole cross section. On the contrary, as for CFSHS stub columns without PBR, its ultimate compression strength loading through the whole cross section is observably higher than that loading through concrete alone.

(3) PBR can make the steel tube and filled-in concrete work together, which results in the axial load shared by hollow steel section and filled-in concrete section regardless of loading through steel or concrete alone. The axial strain distribution model of steel tube section along the height for CFSHS with PBR is proposed.

(4) The failure mode of CFSHS with PBR is summarized in this paper. If the stiffness of PBR is large enough, the columns are failed as "double wave". Otherwise, the plate is emerged as "single wave", whose failure mode is the same as CFSHS without PBR. Further research of the minimum stiffening rigidity for CFSHS with PBR is recommended to confirm the structural dimension reasonable structure and size of PBR.

\section{Acknowledgements}

This paper is supported by the National Natural Science Foundation of China (Contract No. 51778058), Natural Science Foundation of Shaanxi Provincial Department of Science and Technology (2018JQ5219), Natural Science Foundation of Qinghai Provincial Department of Transport (2017-ZI 13), Natural Science Foundation of Shaanxi Provincial Department of Transport (2017-30T).

\section{REFERENCES}

[1] Cheng, G., Liu, Y. J., \& Jiang, L. (2014). Research on Concrete-Filled Rectangular Steel Tube Stiffeners and Axial Compression Bearing Capacity. Advanced Materials Research, 1065-1069, 1092-1096. https://doi.org/10.4028/www.scientific.net/AMR.1065-1069.1092

[2] Petrus, C., Abdul Hamid, H., Ibrahim, A., \& Parke, G. (2010). Experimental behaviour of concrete filled thin walled steel tubes with tab stiffeners. Journal of Constructional Steel Research, 66(7), 915-922. https://doi.org/10.1016/j.jcsr.2010.02.006

[3] Lei, J., Yongjian, L., \& Amir, F. (2018). Stress concentration factors in joints of square hollow section (SHS) brace and concrete-filled SHS chord under axial tension in brace. ThinWalled Structures, 132, 79-92. https://doi.org/10.1016/j.tws.2018.08.014

[4] Liu, B., Liu, Y., Zhou, X., Zhou, L. I., \& Wang, K. (2017). Design of mid-span fabricated RCFST composite truss bridge. Journal of Traffic \& Transportation Engineering, 17(4), 21-31.

[5] Liu, Y., Cheng, G., Zhang, N., \& Zhang, J. (2014). 
Experimental research on concrete-filled square steel tubular columns stiffened with PBL. Journal of Building Structures, 35(10), 39-46. https://doi.org/10.1016/S0143-974X(03)00124-X

[6] Valente, I. \& Cruz, P. J. S. (2004). Experimental analysis of Perfobond shear connection between steel and lightweight concrete. Journal of Constructional Steel Research, 65(10), 1954-1963.

[7] Liu, Y. L., Xiong, Z., Feng, Y., \& Jiang, L. (2017). Concretefilled rectangular hollow section $X$ joint with Perfobond Leister rib structural performance study: Ultimate and fatigue experimental Investigation. Steel and Composite Structures, 24(4), 455-465.

[8] Xiong, Z. H., Liu, Y. J., Zhang, N., \& Song, S. L. (2014). Structural Performance of Concrete-Filled Rectangular Steel Tubular Joints with Perfobond Rib in Bridges using Damage Model. Geo-hubei International Conference on Sustainable Civil Infrastructure, 46-53. https://doi.org/10.1061/9780784478530.006

[9] Jin, Z., Zhang, N., Shang, B., \& Li, H. (2017). Experiment on Mechanical Properties of Concrete-filled Square Steel Tube with PBL. Journal of Civil Engineering and Management, 34(1), 94-112.

[10] Jiang, L., Liu, Y., Fam, A., \& Wang, K. (2019). Fatigue behaviour of non-integral Y-joint of concrete-filled rectangular hollow section continuous chord stiffened with perfobond ribs. Engineering Structures, 191, 611-624. https://doi.org/10.1016/j.engstruct.2019.04.089

[11] Tian, Z. \& Liu, Y. (2019). A review on application of composite truss bridges composed of hollow structural section members. Journal of Traffic and Transportation Engineering (English Edition), 6(1), 94-108. https://doi.org/10.1016/j.jtte.2018.12.001

[12] Xu, C., Yang, Y., Xin, T., \& Liu, J. (2019). Experimental Research on Static Behavior of Stiffened T-Shaped Concrete-Filled Steel Tubular Stubs Subjected to Concentric Axial Loading. International Journal of Steel Structures, 19(2), 591-602. https://doi.org/10.1007/s13296-018-0145-4

[13] Hasan, H., Ekmekyapar, T., \& Shehab, B. (2019). Mechanical performances of stiffened and reinforced concrete-filled steel tubes under axial compression. Marine Structures, 65, 417-432. https://doi.org/10.1016/j.marstruc.2018.12.008

[14] Cheng, G., Liu, Y., Tian, Z., Qiu, J., \& Xiong, Z. (2015). Tensile behavior of PBL stiffened concrete-filled rectangular steel tubular unequal T-connections. Journal of Chang'an University (Natural Science Edition), 35(3), 83-90.

[15] Yang, H., Lam, D., \& Gardner, L. (2008). Testing and analysis of concrete-filled elliptical hollow sections. Engineering Structures, 30(12), 3771-3781. https://doi.org/10.1016/j.engstruct.2008.07.004

[16] Chen, B., Sheng, Y., Fam, A., \& Wei, J. (2017). Torsional behavior of a new dumbbell-shaped concrete-filled steel tubes. Thin-Walled Structures, 110, 35-46. https://doi.org/10.1016/j.tws.2016.10.016

[17] ABAQUS (2012), Abaqus user's manual; Version 6.12, Dassault Systems.

[18] Liu, Y., Cheng, G., Zhang, N., \& Zhang, J. (2014). Mechanical Properties Analyks of Concrete-filled Square Steel Tube Columns Stiffened with PBL. Journal of Building Structures, 35(10), 36-49.

[19] Liu, Y., Li, H., Zhang, N., Liu, J., \& Sun, X. (2015). Interface bond-slip performance of rectangular concrete-filled steel tube stiffened by PBL. Journal of Architectural and Civil Engineering, 32(5), 1-7.

[20] Liu, Y., Liu, J., Guo, Y., \& Chi, J. (2007). Bond-slip mechnics behaviors of structures concrete filled steel tubes. Journal of Chang'anUniversity (Natural Science Edition), 27(2), 53-57.

\section{Contact information:}

\section{Gao CHENG}

(1) School of Highway, Chang'an University,

Xi'an, Shaanxi, China

(2) Shaanxi Provincial Major Laboratory for Highway Bridge \& Tunnel,

Xi'an, Shaanxi, China

Yongjian LIU

Corresponding author

(1) School of Highway, Chang'an University,

Xi'an, Shaanxi, China

(2) Shaanxi Provincial Major Laboratory for Highway Bridge \& Tunnel

Xi'an, Shaanxi, China

E-mail: lyj.chd@gmail.com

Hui LI

School of Highway, Chang'an University,

Xi'an, Shaanxi, China

\section{Ning ZHANG}

College of Water Resources and Architecturally Engineering,

Northwest A\&F University,

Yangling, Shaanxi, China

\section{Jufeng SU}

(1) School of Highway, Chang'an University,

Xi'an, Shaanxi, China

(2) Shaanxi Provincial Major Laboratory for Highway Bridge \& Tunnel,

Xi'an, Shaanxi, China 